
$\$$ Research Square
Preprints are preliminary reports that have not undergone peer review.
They should not be considered conclusive, used to inform clinical practice, or referenced by the media as validated information.

\title{
Effect of different prophylactic therapies on the recurrence pattern of esophageal squamous cell carcinoma after radical surgery
}

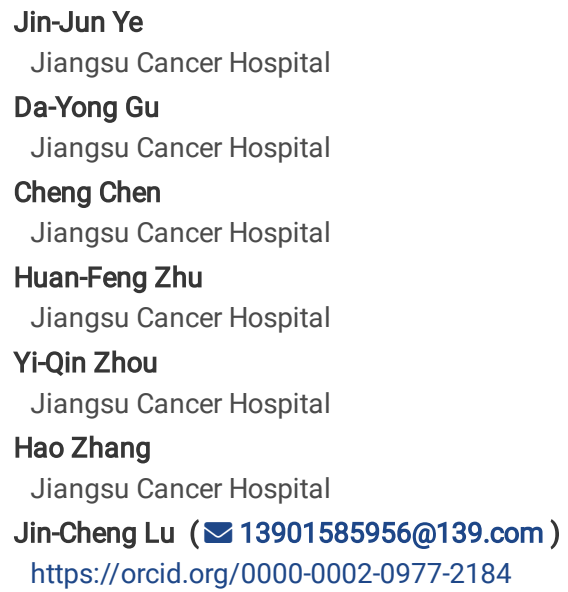

Research

Keywords: esophageal cancer, surgery, radiotherapy, chemotherapy, radiochemotherapy

Posted Date: March 6th, 2020

DOI: https://doi.org/10.21203/rs.3.rs-16276/v1

License: (c) (i) This work is licensed under a Creative Commons Attribution 4.0 International License. Read Full License 


\begin{abstract}
Background To compared the patterns of lymph node recurrence after different prophylactic therapies to identify specific and effective target areas for prophylactic radiotherapy.
\end{abstract}

Methods This retrospective study enrolled patients with recurrence from August 2011 to November 2015, who underwent different prophylactic therapies for esophageal squamous cell carcinoma after radical surgery previously. The patients were divided into unprotected, radiotherapy, chemotherapy, and radiochemotherapy groups. The recurrence patterns between these groups were compared.

Results A total of 186 patients who met the above criteria were enrolled. The recurrence ratios of regional lymph nodes were $84.2 \%, 31.3 \%, 84.0 \%$, and $48.0 \%$ in the unprotected, radiotherapy, chemotherapy, and radiochemotherapy groups, respectively. The recurrence ratio of regional lymph nodes in patients who received radiotherapy was significantly decreased $(P=0.009)$. The recurrence ratio of superior mediastinal lymph node was significantly lower than those of the chemotherapy and unprotected groups $(P=0.000)$. The recurrence ratios of the radiotherapy group with and without epigastrium coverage were $4 / 16$ and $4 / 25$, respectively, indicating no statistical difference with those of other groups $(P=0.259)$. The recurrence ratios with and without the coverage of anastomotic sites were $2 / 19$ and $3 / 22$, respectively, revealing no statistical difference with those of other groups $(P=0.712)$.

Conclusion Prophylactic radiotherapy can significantly reduce the recurrence of regional lymph nodes, especially lymph node recurrence on the superior mediastinum.

\title{
Background
}

Adjuvant therapies after radical surgery for esophageal cancer generally include the prophylactic therapy of R0 excision for non-recurrent patients and the salvage therapy of non-R0 excision or R0 excision for recurrent patients. ${ }^{1-6}$ Main research directions on prophylactic radiotherapy after radical surgery for esophageal cancer focus on lymph node recurrence in patients who underwent R0 excision, especially on determining the target region for prophylactic radiotherapy according to the post-recurrence range of lymph nodes. ${ }^{7-12}$ However, studies on lymph node recurrence after prophylactic therapies of high-risk regions are limited. ${ }^{13,14}$ On the basis of previous studies, ${ }^{6,8,15-18}$ we compared the patterns of lymph node recurrence after different prophylactic therapies to identify specific and effective target areas for prophylactic radiotherapy.

\section{Methods \\ Inclusion Criteria}

This retrospective study enrolled patients with recurrence from August 2011 (when electronic records were adopted at our hospital) to November, 2015, who underwent different prophylactic therapies for esophageal squamous cell carcinoma after radical surgery previously. Those who received neoadjuvant therapy before surgery were excluded from this study because patients who undergo radical surgery after neoadjuvant therapy do not usually require adjuvant therapy. Informed consent was obtained in all patients before treatment, and some patients had participated in clinical trials (ChiCTR-TNC-10001140).

\section{Diagnosis of Recurrence}

Some cases of lymph node recurrences are pathologically confirmed. ${ }^{18}$ Two consecutive CT scans at an interval of $\geq 1$ month revealed that lymph nodes either continued to increase at a small diameter of $>1 \mathrm{~cm}$ or did not increase, but clinical symptoms considerably worsened. Patients without pathological diagnosis were discussed at department meetings before salvage therapy.

The mode of recurrence was classified into the following three patterns. (1) Local recurrence was defined as anastomotic or residual esophagus and stomach recurrence. (2) Regional recurrence occurs either in the supraclavicular area or in the mediastinum (the inferior margin of azygos arch and inferior pulmonary vena is divided into upper, middle, and lower parts) or epigastrium at the site of previous esophageal resection and nodal clearance. (3) Distant recurrence was described as hematogenous if it developed within a solid organ or within the peritoneal cavity. When a patient showed recurrence in multiple distant organs, the organ where the recurrence was initially detected organ was selected as the recurred organ. If a second recurrence was detected within 4 weeks after the first occurrence, then the occurrence was considered synchronous. Histologic, cytologic, or unequivocal radiologic proof was required before diagnosing a recurrence.

\section{Prophylactic Therapy Regimen}

Patients were placed in a supine-position-vacuum bag with crossed fingers and hands at head top; the supraclavicular areas and superior mediastinum were irradiated in patients with upper thoracic esophageal cancer; the supraclavicular areas and superior and inferior mediastinum were irradiated in patients with middle thoracic esophageal cancer; and the superior and inferior mediastinum were irradiated in patients with low thoracic esophageal cancer. ${ }^{6,16}$ The epigastrium was also selectively irradiated in some patients. The planning target volume was generated using a uniform $0.5 \mathrm{~cm}$ expansion beyond the borders of the clinical target volume. All organs at risk, such as heart, lung, and liver, were outlined. The total dose of external radiotherapy provided was 50 Gy in 25 fractions. Patients were treated 5 days per week at $2.0 \mathrm{~Gy} / \mathrm{d}$. All radiation treatments were delivered as intensity-modulated radiotherapy at $<6$ weeks after surgery. Megavoltage photon energy of $\geq 6 \mathrm{MV}$ was used. Every effort was made to reduce exposure to lungs, heart, spinal cord, kidney, and liver.

Patients received $20 \mathrm{mg} / \mathrm{m}^{2}$ docetaxel as a 30-minute intravenous (IV) infusion every week for 5 weeks. One hour before chemotherapy, patients received $10 \mathrm{mg}$ IV dexamethasone to prevent hypersensitivity reactions. Other main chemotherapy regimens were $80 \mathrm{mg} / \mathrm{m}^{2} \mathrm{docetaxel}$ and $80 \mathrm{mg} / \mathrm{m}^{2}$ nedaplatin.

\section{Statistical Analysis}


Patients who met these criteria were divided into four groups: unprotected, radiotherapy, chemotherapy, and radiochemotherapy groups. The recurrence patterns of these groups were compared. Recurrence time was measured from the beginning of surgery until the first occurrence of failure. Statistical analysis was performed with SPSS version 21.0 (SPSS Inc., Chicago IL). Groups were compared using Chi-squared test or Fisher's test. Statistical significance was defined as a two-sided $P$ value of $<0.05$.

\section{Results}

A total of 186 patients (159 males and 27 females) conforming to the above conditions were included. The average age of these respondents at operation was 59 years old (range: 44-83). A total of 178 cases underwent left thoracic two-incision lymphadenectomy, whereas only 8 cases underwent right thoracic three-incision lymphadenectomy. A total of 2,182 lymph nodes were removed, 225 of which were pathologically positive, and the metastasis ratio was $10.3 \%$. Moreover, 79 patients were diagnosed with positive lymph nodes, indicating a metastatic rate of $42.5 \%$. The disease course of the patients was divided according to the American Joint Committee on Cancer 7th edition. The pN stages of N0, N1, N2, and N3 involved 107, 49, 23, and 7 patients, respectively. The PT stages of T0, T1, T2, T3, and T4 were observed in 2, 29, 54, 95, and 6 patients, respectively. The details are presented in Table 1.

Table 1

Patient and Tumor Characteristics

\begin{tabular}{|c|c|c|c|c|c|}
\hline & $\mathrm{n}$ & Unprotected & Radiotherapy & Chemotherapy & Radiochemotherapy \\
\hline $\begin{array}{l}\text { Gender } \\
\text { Male } \\
\text { Female }\end{array}$ & $\begin{array}{l}159 \\
27\end{array}$ & $\begin{array}{l}76 \\
19\end{array}$ & $\begin{array}{l}14 \\
2\end{array}$ & $\begin{array}{l}46 \\
4\end{array}$ & $\begin{array}{l}23 \\
2\end{array}$ \\
\hline $\begin{array}{l}\text { Age (years) } \\
\text { Median } \\
\text { Range }\end{array}$ & & $\begin{array}{l}61 \\
45-83\end{array}$ & $\begin{array}{l}61 \\
51-74\end{array}$ & $\begin{array}{l}58 \\
46-73\end{array}$ & $\begin{array}{l}55 \\
44-73\end{array}$ \\
\hline $\begin{array}{l}\text { Location } \\
\text { Upper } \\
\text { Middle } \\
\text { Lower }\end{array}$ & $\begin{array}{l}10 \\
126 \\
50\end{array}$ & $\begin{array}{l}8 \\
67 \\
20\end{array}$ & $\begin{array}{l}0 \\
12 \\
4\end{array}$ & $\begin{array}{l}1 \\
35 \\
14\end{array}$ & $\begin{array}{l}1 \\
12 \\
12\end{array}$ \\
\hline $\begin{array}{l}\text { pT category } \\
\text { T0 } \\
\text { T1 } \\
\text { T2 } \\
\text { T3 } \\
\text { T4 }\end{array}$ & $\begin{array}{l}2 \\
29 \\
54 \\
95 \\
6\end{array}$ & $\begin{array}{l}2 \\
24 \\
33 \\
34 \\
2\end{array}$ & $\begin{array}{l}0 \\
1 \\
5 \\
10 \\
0\end{array}$ & $\begin{array}{l}0 \\
4 \\
12 \\
31 \\
3\end{array}$ & $\begin{array}{l}0 \\
0 \\
4 \\
20 \\
1\end{array}$ \\
\hline $\begin{array}{l}\text { pN category } \\
\text { N0 } \\
\text { N1 } \\
\text { N2 } \\
\text { N3 }\end{array}$ & $\begin{array}{l}107 \\
49 \\
23 \\
7\end{array}$ & $\begin{array}{l}75 \\
14 \\
5 \\
1\end{array}$ & $\begin{array}{l}9 \\
5 \\
2 \\
0\end{array}$ & $\begin{array}{l}17 \\
20 \\
9 \\
4\end{array}$ & $\begin{array}{l}6 \\
10 \\
7 \\
2\end{array}$ \\
\hline
\end{tabular}

Among the selected patients, 139 showed lymph node recurrence (recurrence ratio: $74.7 \%$ ). In non-epigastric abdominal lymph node recurrence, five cases were excluded. The distribution of pathologically positive and recurrent lymph nodes is presented in Table 2.

Table 2

The distribution of pathologically positive at operation and recurrent lymph nodes(\%)

\begin{tabular}{|lllllll}
\hline & $\mathbf{n}$ & Supraclavicular & \multicolumn{3}{l|}{$\begin{array}{l}\text { Mediastinum } \\
\text { Superior Middle Inferior }\end{array}$} \\
\hline Pathological positive & 79 & $2(2.5)$ & $21(26.6)$ & $33(41.8)$ & $21(26.6)$ \\
\hline Unprotected & 20 & $2(10.0)$ & $4(20.0)$ & $6(30.0)$ & $5(25.0)$ & $42(53.2)$ \\
\hline Radiotherapy & 7 & $0(0.0)$ & $2(28.6)$ & $3(42.9)$ & $1(14.3)$ & $4(45.0)$ \\
\hline Chemotherapy & 33 & $0(0.0)$ & $7(21.2)$ & $15(45.5)$ & $8(24.2)$ & $19(57.8)$ \\
\hline Radiochemotherapy & 19 & $0(0.0)$ & $8(42.1)$ & $9(47.4)$ & $7(36.8)$ \\
\hline Recurrence & 139 & $45(32.4)$ & $76(54.7)$ & $30(21.6)$ & $9(6.5)$ \\
\hline Unprotected & 80 & $27(33.8)$ & $46(57.5)$ & $18(22.5)$ & $4(5.0)$ \\
\hline Radiotherapy & 5 & $4(80.0)$ & $1(20.0)$ & $0(0.0)$ & $0(0.0)$ \\
\hline Chemotherapy & 42 & $10(23.8)$ & $25(59.5)$ & $9(21.4)$ & $5(11.9)$ \\
\hline Radiochemotherapy & 12 & $4(33.3)$ & $4(33.3)$ & $3(25.0)$ & $0(0.0)$ \\
\hline Note: The number of positive cases is less than the sum of sub-items because some patients have multiple regional lymph node recurrence or positive. \\
\hline
\end{tabular}


Table 3 illustrates that the regional lymph node recurrence ratios of unprotected, radiotherapy, chemotherapy, and radiochemotherapy groups were $84.2 \%$, $31.3 \%, 84.0 \%$, and $48.0 \%$, respectively. A total of 23 patients showed recurrence at anastomotic sites (recurrence ratio: $12.4 \%$ ), 10 of which were accompanied with lymph node recurrence, 1 with pulmonary metastasis, 1 with osseous metastasis, 2 with liver and osseous metastasis, 1 with pulmonary and osseous metastasis, and 1 with scalp and liver metastasis. The median time of the first recurrence was 13 months (range: 1-260 months).

Table 3

Recurrence patterns after different prophylactic therapies (\%)

\begin{tabular}{|lllll|}
\hline Recurrent sites & $\begin{array}{l}\text { Unprotected } \\
\mathbf{n = 9 5}\end{array}$ & $\begin{array}{l}\text { Radiotherapy } \\
\mathbf{n = 1 6}\end{array}$ & Chemotherapy $\mathbf{n = 5 0}$ & Radiochemotherapy $\mathbf{n}=\mathbf{2 5}$ \\
\hline Lymph node & $80(84.2)$ & $5(31.3)$ & $42(84.0)$ & $12(48.0)$ \\
\hline Anastomotic & $14(17.5)$ & $2(12.5)$ & $4(8.0)$ & $3(12.0)$ \\
\hline Esophagus & $2(2.5)$ & $0(0.0)$ & $0(0.0)$ & $0(0.0)$ \\
\hline Stomach & $1(1.3)$ & $0(0.0)$ & $0(0.0)$ & $0(0.0)$ \\
\hline Chest wall & $0(0.0)$ & $1(6.3)$ & $1(2.0)$ & $0(0.0)$ \\
\hline Pulmonary & $1(1.3)$ & $5(31.3)$ & $2(4.0)$ & $7(28.0)$ \\
\hline Bone & $5(6.3)$ & $2(12.5)$ & $5(10.0)$ & $3(12.0)$ \\
\hline Liver & $4(5.0)$ & $0(0.0)$ & $1(2.0)$ & $0(0.0)$ \\
\hline Brain & $0(0.0)$ & $3(18.8)$ & $0(0.0)$ & $1(4.0)$ \\
\hline Scalp & $1(1.3)$ & $0(0.0)$ & $0(0.0)$ & $0(0.0)$ \\
\hline Adrenal gland & $1(1.3)$ & $0(0.0)$ & $0(0.0)$ & $0.0)$ \\
\hline
\end{tabular}

Table 4 presents the recurrence ratio of regional lymph nodes in patients who received radiotherapy. The combined group of radiotherapy and radiochemotherapy showed significantly decreased recurrence ratio $(P=0.009)$. The recurrence ratio of superior mediastinal lymph node in the radiotherapy and radiochemotherapy groups was significantly lower than that of the chemotherapy and unprotected groups $(P=0.000)$. The recurrence ratios of the radiotherapy group with and without epigastrium coverage were 4/16 and 4/25, respectively, indicating no statistical difference compared with those of other groups $(P=0.259)$. The recurrence ratios with and without the coverage of anastomotic sites were $2 / 19$ and $3 / 22$, respectively, also revealing no statistical difference with those of other groups $(P=0.712)$.

Table 4

Comparison of recurrence patterns after different prophylactic therapies

\begin{tabular}{|llllll|}
\hline Location & \multicolumn{2}{l}{$\begin{array}{l}\text { Radiotherapy and radiochemotherapy } \\
\text { Outfield Infield }\end{array}$} & $\begin{array}{l}\text { Chemotherapy } \\
\mathbf{n = 5 0}\end{array}$ & $\begin{array}{l}\text { Unprotected } \\
\mathbf{n = 9 5}\end{array}$ & P \\
\hline Supraclavicular & $2 / 10$ & $6 / 31$ & 10 & 27 & 0.856 \\
\hline Superior mediastinum & $0 / 3$ & $5 / 38$ & 25 & 46 & 0.000 \\
\hline Middle mediastinum & $0 / 2$ & $3 / 39$ & 9 & 18 & 0.057 \\
\hline Inferior mediastinum & $0 / 15$ & $0 / 26$ & 5 & 4 & 0.098 \\
\hline Epigastrium & $4 / 25$ & $4 / 16$ & 3 & 7 & 0.259 \\
\hline Anastomotic & $3 / 22$ & $2 / 19$ & 4 & 14 & 0.712 \\
\hline Lymph node & 17 & & 42 & 80 & 0.009 \\
\hline Metastasis & 19 & & 10 & 12 & 0.068 \\
\hline Esophagus and stomach & 0 & & 0 & 3 & - \\
\hline
\end{tabular}

\section{Discussion}

Understanding the recurrence pattern of patients with cancer is very important for clinical decision-making. Based on our results, regional lymph nodes remain as the primary site of recurrence after radical surgery for esophageal cancer, showing a $74.7 \%$ recurrence ratio. The recurrence ratios of lymph nodes in the supraclavicular area, superior mediastinum, middle mediastinum, inferior mediastinum, and epigastrium were $32.4 \%, 54.7 \%, 21.6 \%, 6.5 \%$, and $12.9 \%$, respectively (Table 2), conforming to previous reports. ${ }^{9,10}$ The recurrence ratios of regional lymph nodes in the unprotected, radiotherapy, chemotherapy, and radiochemotherapy groups were $84.2 \%, 31.3 \%, 84.0 \%$, and $48.0 \%$, respectively (Table 3 ). These findings indicate that radiotherapy could remarkably decrease the recurrence of regional lymph nodes.

Pathologically positive lymph nodes during the operation of esophageal cancer indicated remarkably different distribution patterns of recurrent lymph nodes in the unprotected group after radical surgery. Therefore, post-operation prophylactic radiotherapy range must first be determined according to post-operative 
recurrence range. However, the distribution of pathologically positive lymph nodes can be utilized to determine the range of radical radiotherapy. Table 2 shows that the distribution of relapsed lymph nodes after different prophylactic therapies was different. Specifically, the recurrence ratio of superior mediastinal lymph nodes after prophylactic radiotherapy was considerably lower than that of the unprotected and chemotherapy groups. However, the recurrence ratio of epigastrium lymph nodes was similar among different groups, indicating the favorable effect of prophylactic radiotherapy on superior mediastinal lymph node but its unfavorable effect on epigastric lymph node. This finding was further verified in the data in Table 4 . The recurrence ratio of superior mediastinal lymph nodes was remarkably lower than that of other groups. In groups involving radiotherapy, the recurrence ratios with and without the coverage of epigastric lymph nodes were $4 / 16$ and $4 / 25$, respectively, both of which show no statistically significant difference with those of other groups. The radiochemotherapy group exhibited a high ratio of epigastric recurrence, reaching $58.3 \%$ (Table 2). Whether the high ratio was due to a relative decrease in the ratio of the upper mediastinum or other reasons is unclear. Therefore, the clinical design of prophylactic radiotherapy range must consider not only highrecurrence regions but also the effects of prophylactic radiotherapy on the reduction of recurrence rate in these regions.

The recurrence ratio of anastomotic sites was $12.4 \%$. No significant difference in recurrence ratio was observed among different prophylactic therapy groups (Table 3), indicating that the coverage of anastomotic sites was not important. A balance between recurrence rate and the increased occurrence of strictures and fistula by irradiation has been discussed in the past era of 2D radiotherapy. Adopting the coverage of anastomotic sites in the exposure field is not suggested because of the limitations of radiotherapy technologies. Reaching the same exposure dose with other regions under deliberate coverage is difficult. Thus, whether the anastomotic sites are in the exposure range is uncertain. With respect to current radiotherapy technologies, covering anastomotic sites is easy, but the expected preventive effect is not achieved, as manifested by the small reduction of recurrence rate. In this study, the recurrence ratios of radiotherapy groups with and without the coverage of anastomotic sites are $2 / 19$ and $3 / 22$, respectively. Both ratios showed no significant difference with those of other groups.

Although chemotherapy can theoretically reduce distant metastasis, such reduction was not observed in this study. Thus, relevant causes remain unknown. Table 4 shows that the chemotherapy and unprotected groups exhibited no significant difference in the proportion of distant metastasis. By contrast, radiotherapy increased the proportion of distant metastasis while reducing the recurrence ratio of regional lymph nodes. Thus, the differences of various groups approached statistical significance.

Existing studies only involve patients with post-operative recurrence of esophagus cancer. Therefore, recurrence can only provide a proportion rather than a real recurrence rate. This study only involved retrospective research with one center and limited respondents. Although preliminary conclusions on prophylactic therapy can be drawn according to the results of this study, different recurrence modes after various prophylactic therapies can only be interpreted, and the

necessity of prophylactic therapy cannot be determined. Furthermore, different pathological patterns may cause differences in recurrence modes. ${ }^{19}$ Given that this study only involves patients with squamous carcinoma, the relevant results and deduced conclusions may not be in applicable to patients with adenocarcinoma.

\section{Conclusions}

Prophylactic radiotherapy can significantly reduce the recurrence of regional lymph nodes, especially lymph node recurrence on the superior mediastinum. However, reducing the recurrence of epigastric lymph node and anastomotic sites is ineffective. The clinical design of prophylactic radiotherapy range must consider not only high-recurrence regions but also the effects of prophylactic radiotherapy on the reduction of recurrence rate in these regions.

\section{Declarations}

List of abbreviations

Not applicable

Ethics approval and consent to participate

Not applicable

Consent for publication

Not applicable

Availability of data and materials

Not applicable

Competing interests

The authors declare that they have no competing interests

Funding

Not applicable 
Authors' contributions

Jin-Cheng Lu: Planned, wrote, revised, and supervised the writing and concept of the article. Jin-Jun Ye: Wrote, revised, and edited the article. Da-Yong Gu: Analysis of data and statistics. Cheng Chen: Reviewed and edited the article. Huan-Feng Zhu, Yi-Qin Zhou, and Hao Zhang: Reviewed and edited the article. All authors read and approved the final manuscript.

Acknowledgements

This work was supported by Six Talent Peaks Project in Jiangsu Province (CN) [grant numbers: LGY2016024];Jiangsu Young Talents Program[grant numbers: ।

\section{References}

1 Xiao ZF, Yang ZY, Liang J, et al. Value of radiotherapy after radical surgery for esophageal carcinoma: a report of 495 patients. Ann Thorac Surg 2003 ; 75:325-8.

2 Schreiber D, Rineer J, Vongtama D, et al. Impact of postoperative radiation after esophagectomy for esophageal cancer. J Thorac Oncol 2010; 5:244-50.

3 Chen JQ, Pan JJ, Zheng XW, et al. Number and location of positive nodes, postoperative radiotherapy, and survival after esophagectomy with three-field lymph node dissection for thoracic esophageal squamous cell carcinoma. Int J Radiat Oncol Biol Phys 2012; 82:475-82.

4 Wong AT, Shao M, Rineer J, Lee A, Schwartz D, Schreiber D. The impact of adjuvant postoperative radiation therapy and chemotherapy on survival after esophagectomy for esophageal carcinoma. Ann Surg 2017; 265:1146-51.

5 Yang JS, Zhang WC, Xiao ZF, et al. The impact of postoperative conformal radiotherapy after radical surgery on survival and recurrence in pathologic T3NOMO esophageal carcinoma: A propensity score-matched analysis. J Thorac Oncol 2017; 12:1143-51.

6 Tao H, Zhou YQ, Yao CY, Gu DY, Chen W, Lu JC. Phase II trial of intensity-modulated radiotherapy concurrent with chemotherapy for postoperative nodepositive esophageal squamous cell carcinoma. Oncol Res 2017; 25:1357-62.

7 Mariette C, Balon JM, Piessen G, Fabre S, van Seuningen I, Triboulet JP. Pattern of recurrence following complete resection of esophageal carcinoma and factors predictive of recurrent disease. Cancer 2003; 97:1616-23.

$8 \mathrm{Lu}$ JC, Tao H, Zhang YQ, et al. Extent of prophylactic postoperative radiotherapy after radical surgery of thoracic esophageal squamous cell carcinoma. Dis Esophagus 2008; 21:502-7.

9 Cai WJ, Xin PL. Pattern of relapse in surgical treated patients with thoracic esophageal squamous cell carcinoma and its possible impact on target delineation for postoperative radiotherapy. Radiother Oncol 2010; 96:104-7.

10 Liu Q, Cai XW, Wu B, Zhu ZF, Chen HQ, Fu XL. Patterns of failure after radical surgery among patients with thoracic esophageal squamous cell carcinoma: Implications for the clinical target volume design of postoperative radiotherapy. Pols One. 2014; 9:e97225.

11 Liu J, Cai XW, Liu Q, Li HX, Cheng Y, Fu XL. Characteristics of the local recurrence pattern after curative resection and values in target region delineation in postoperative radiotherapy for lower thoracic esophageal squamous cell cancer. Thorac Cancer 2017; 8:630-3.

12 Yamashita K, Watanabe M, Mine S, et al. Patterns and outcomes of recurrent esophageal cancer after curative esophagectomy. World J Surg 2017; 41:2337-44.

13 Hsu PK, Chen HS, Huang CS, et al. Patterns of recurrence after oesophagectomy and postoperative chemoradiotherapy versus surgery alone for oesophageal squamous cell carcinoma. Br J Surg 2017; 104:90-7.

14 Wang YH, Li Z, Ye DM, et al. A retrospective study of pattern of recurrence after radical surgery for thoracic esophageal carcinoma with or without postoperative radiotherapy. Oncol Lett 2018; 15:4033-9.

15 Lu JC, Tao H, Chen ZZ, Qian PD. Prognostic factors of radiotherapy in patients with node-positive thoracic esophageal squamous cell carcinoma after radical surgery. Dis Esophagus 2009; 22:490-5.

$16 \mathrm{Lu} \mathrm{JC}$, Kong C, Tao H. Radiotherapy with or without concurrent chemotherapy for lymph node recurrence after radical surgery of thoracic esophageal squamous cell carcinoma. Int J Radiat Oncol Biol Phys 2010; 78:710-4.

17 Lu JC, Tao H, Song D, Chen C. Recurrence risk model for esophageal cancer after radical surgery. Chin J Cancer Res 2013; 25:549-55.

18 Zhou YQ, Ding NX, Wang LJ, Liu W, Jiang M, Lu JC. Salvage radiochemotherapy for lymph node recurrence after radical surgery of esophageal cancer. Medicine 2018; 97:5.

19 Xi M, Xu C, Liao ZX, et al. The impact of histology on recurrence patterns in esophageal cancer treated with definitive chemoradiotherapy. Radiother Oncol 2017; 124:318-24. 